\title{
Salud Pública y Psiquiatría
}

RESUMEN: La salud pública y la psiquiatría comunitaria emergen, y sobre todo alcanzan sus momentos de mayor desarrollo, en tiempos de sensibilidad social, y se empobrecen cuando se debilita el lazo social. En este artículo se analiza la relación entre salud pública y clínica psiquiátrica, siguiendo las distintas fases descritas para ambas disciplinas, desde los orígenes del proyecto político fundador de la edad contemporánea. Se relacionan los viejos debates entre la medicina psicológica y la medicina de la lesión y entre la consideración de la colectividad o la individualización del enfermar y las consiguientes formas de organizar la asistencia sanitaria.

PALABRAS CLAVE: Salud Pública y psiquiatría, psiquiatría comunitaria, psiquiatría biológica.
SUMMARY: The public health and the community psychiatry emerge, and they reach their moments of more development, mainly in times of social sensibility, and they impoverish when the social knot weakens. In this article the relationship between public health and psychiatric clinic is analysed, following the different phases described for both disciplines, from the origins of the political founder project of the contemporary age. The old debates between the psychological medicine and the medicine of the lesion and between the consideration of the collective or the individualisation of falling ill and the consequent forms of organising the sanitary attendance are related.

KEY WORDS: Public Health and Psychiatry, Communitary Psychiatry, Biological Psychiatry.

Se habla de Nueva Salud Pública como se habla de nueva y de vieja psiquiatría. Pero viejo y nuevo son expresiones ambiguas, tanto para la salud pública como para la psiquiatría. Lo viejo y lo nuevo hay que situarlo históricamente, aunque hayamos perdido la confianza ciega en el progreso que inundó el pensamiento ilustrado y el materialismo dialéctico. Castilla del Pino, en un libro memorable, Vieja y nueva psiquiatría (1971), vincula lo viejo con la adscripción a un pensamiento dogmático y estereotipado: mecanismo de defensa ante lo nuevo, pero anticipa algo que aquí nos importa al señalar que la psiquiatría no es una ciencia autónoma. Acepta aquello que le es útil, venga de donde viniere. Y en este sentido la psiquiatría de un tiempo es la ciencia de ese tiempo (1). Hay quienes piensan que ni la Nueva Salud Pública es nueva, ni la otra se ha hecho vieja: es la salud pública de siempre pero queriendo abordar todos los factores que inciden sobre la salud: estilos de vida, biología humana, medio ambiente y actuación del sistema sanitario (2). El hecho es que lo que hoy llamamos Nueva Salud Pública emerge cuando irrumpen nociones más positivas de salud y más comunitarias de asistencia, que confieren al individuo y a la comunidad capacidad para aumentar su control sobre los determinantes de su 
salud y, por tanto, para mejorarla (capacidad de la comunidad para influir en la planificación y en la gestión de los asuntos y programas que afectan a su salud). )Pero, ¿quién representa hoy a la nueva psiquiatría, la salud mental comunitaria o la psiquiatría basada en la evidencia? Es otra la antinomia.

Hay momentos en la historia de los pueblos en los que se traba el lazo social, que la colectividad, la comunidad se articula de forma más solidaria, momentos de progreso y hay otros momentos donde se producen retrocesos más o menos brutales que alojan a las sociedades en el individualismo, en el acomodaticio sálvese quien pueda o en actitud depredadora en la jungla del poder y el dinero. La psiquiatrá y la salud pública surgieron y se desarrollaron en tiempos de cambio social, de ruptura, en sociedades abiertas al progreso, a la aventura del descubrimiento.

Reacción y progreso son pares antitéticos que encuentran su expresión clínica y teórica en otras contraposiciones: somáticos frente a psicologistas, predominio de la lesión frente al espíritu; o dicho en términos más actuales: naturaleza versus cultura; pares antitéticos que se vuelven a encontrar enfrentados al considerar la salud y el enfermar como hechos individuales o sociales y que conllevan consecuentemente modos diferentes de entender la organización de la asistencia y el cuidado.

La sociedad, dice María Zambrano, lo es en sentido estricto sólo donde el individuo actúa y tiene vigencia. Siempre que el individuo sea aplastado o malogrado se recaerá en un tipo de comunidad inferior, ya superada entre nosotros; será un verdadero regreso histórico (3). Hay una sanidad de la colectividad y una clínica del sujeto, y una medicina de los órganos, donde, en palabras del juez Schreber, el único lugar reservado para el enfermo es el de cadáver (4).

Naturaleza, entorno y crianza interactúan para dar origen a cada una de las características y condiciones de la persona, pues ni siquiera la herencia es un valor absoluto e invariable. Si las circunstancias externas cambian, también lo hará la expresión de la herencia. Heredamos, junto con los genes, a los padres, a los amigos y a los lugares que nos habitan (5). El debate se sostiene malamente a poco que indaguemos en las circunstancias sociales y políticas. La reducción a uno u otro parámetro, generalmente a la naturaleza como inmutable -decía Bertolt Brech: «no digáis nunca es natural para que nada parezca inmutable»- esconde posiciones conservadoras, intereses económicos y de poder. El debate no es, ni lo ha sido a través de la historia, modelo médico o psiquiátrica biológica (qué práctica clínica no se sostiene en el cuerpo) frente a medicina o psiquiatría social o dinámica: la pelea está hoy como ayer entre posturas reaccionarias y posturas de progreso.

Tanto el origen como el desarrollo de la salud pública y de la psiquiatría ejemplarizan el peso de las determinaciones políticas y económicas en la actividad científica: el peso de la ideología dominante en la teoría y la práctica sanitaria, en su organización y expresión 
INFORMES

clínica, y las consecuencias sociales de los diferentes modelos de esta secular confrontación, reacción-progreso, que constituye nuestras sociedades.

La salud pública emerge como higiene de las poblaciones en la Francia revolucionaria. A finales de 1794, en el año III revolucionario, se crea $l^{\prime}$ École de Santé como alternativa pedagógica a la conservadora facultad de medicina. Philippe Pinel, para los psiquiatras padre de la psiquiatría y para los salubristas el promotor de la higiene pública francesa (6), es llamado a ocupar la cátedra de Física Médica e Higiene. Un tema entonces candente, que preocupa al gobierno revolucionario. Está en marcha el nuevo proyecto político de la burguesía: una sociedad basada en la salud, el trabajo y la riqueza para todos. Con la revolución se ha roto la vieja relación entre pobreza y enfermedad, en tanto que objetos de la caridad. La salud, a principios del siglo $\mathrm{XIX}$, es un asunto público, un asunto que incide en la riqueza nacional. Un asunto de Estado: el concepto jacobino de salud como rama del orden público, objeto de los comités ciudadanos y de la policía para garantizar el bienestar general. Se cuestiona la idea individual de la higiene y de la salud, que se empieza a concebir dependiendo de las características de la colectividad. Los factores sociales y los estilos de vida, el tema de las costumbres en tanto que favorecedoras o perjudiciales para la salud al que se refiere Pinel en su tratado . «La naturaleza se completa con las costumbres. Las costumbres, productos sociales, cambian la naturaleza y su acción puede ejecutarse por el sistema nervioso» (7). La constitución de la higiene pública en Francia se encuentra influenciada por los enciclopedistas y en un segundo momento por los socialistas utópicos, fundamentalmente Saint-Simón. Con la revolución, París se convierte en la cuna de la Higiene Pública y dentro de este gran movimiento de regulación de la asistencia sanitaria y social, de la psiquiatría. No sólo Pinel, alienistas tan importantes como su discípulo Esquirol -uno de los fundadores de la primera revista de higiene pública aparecida en 1829, Annales d Hygiene Publique et de Medicine Légale; o Foderé -que se ocupa de la epidemiología psiquiátrica-son reconocidos en los orígenes de ambas disciplinas y de los nuevos ordenamientos sanitarios que establecen la obligación del Estado de garantizar el derecho de los pobres a la salud, creando una beneficencia pública territorializada con una serie de médicos asignados a cada colectividad.

El alienismo se constituye ante la necesidad de encontrar un nuevo estatuto social para los locos: de una parte hay que curarlos: es preciso, por tanto, objetivar la enfermedad; de otra parte , como ciudadanos, reclaman de una nueva legalidad. El tratamiento moral de Pinel tiene mucho que ver con la nueva ética revolucionaria, con la incorruptibilidad moral de Robespierre (8).

El Tratado médico-filosófico sobre la enajenación mental o la manía, publicado en 1801 , el año X según el calendario revolucionario, alienta un indudable optimismo terapéutico. El reconocimiento de una subjetividad y de una parte de razón en el alienado restablece el dialogo interrumpido entre la razón del médico y la parcial razón del loco, permitiendo una relación sobre la que se funda el manicomio y el tratamiento moral. Pinel le devuelve al insano su rango de sujeto. «Al reducir la locura a entidad mórbida parece 
como si hubiera hecho lo máximo para dar rostro humano a la enfermedad mental...Debemos agradecerle el haber desmitificado la locura para convertirla en objeto de estudio científico, precisamente porque la locura no es pérdida de la razón sino por que es una manera de ser hombre sin ser el Otro» (9). Posicionamiento que consigue una gran aceptación en el mundo médico y de la cultura en general. «El verdadero tratamiento psíquico - escribe Hegel en la Enciclopedia de las Ciencias del Espíritu - se ajusta al concepto de que la locura no es la pérdida de la razón, ni del lado de la inteligencia ni del lado de la voluntad, sino un simple trastorno del espíritu, una contradicción en la razón que aún existe...Este tratamiento humano, es decir, tan benevolente como razonable, de la locura - Pinel tiene derecho a nuestro más grande reconocimiento por todo lo que ha hecho a este respectosupone que el enfermo es razonable y encuentra en ello un punto de apoyo sólido para tomarlo por ese lado» (10)

Pero este origen optimista y socialmente revolucionario decae a mediados del siglo, coincidiendo con la derrota obrera en la revolución de 1848. Los cambios en la ideología social y científica de la época, junto con la masificación de los asilos, hacen perder el espíritu humanista y esperanzado de los primeros alienistas. Triunfa la tesis de Bayle, dominando la idea de la incurabilidad: la clínica psiquiátrica busca en la lesión las causas de las enfermedades mentales. Con la construcción del concepto de física social o sociología Auguste Comte completa el estudio de todos los fenómenos posible, asentado la primacía de las ciencias naturales

Son años - momentos magistralmente analizados por Marx en dos textos básicos para entender esa época: La lucha de clases en Francia de 1848 a 1850 y El dieciocho brumario de Luis Bonaparte (11) -, en los cuales los espíritus europeos, cansados ya de tanta guerra, buscan un orden estable, pero que armonice con los avances del progreso de la ciencia y, por supuesto, de la industria. «El orden como principio, el progreso como fin» (12)

En España: las efímeras Cortes de Cádiz (1812) van a recoger el ideario asistencial revolucionario, y más tarde, en plena época de radicalismo liberal, un Real Decreto del 27 del 12 de 1821 promulga un marco jurídico para las nuevas instituciones para los alienados: la creación de casas públicas destinadas a «recoger» y curar a los locos de toda especie. Quedan prohibidos «el encierro continuo, la aspereza en el trato, los golpes, grillos y cadenas». El real decreto establece la necesidad de crear espacios específicos de tratamiento para enfermos mentales, rompiendo la promiscua reclusión típica del Antiguo Régimen. Breves momentos, gestos testimoniales, en una España donde predomina el inmovilismo en la pugna entre tradición y ruptura que sacude al siglo y que en los saberes médicos discurre en palabras de Albarracin entre la esperanza y la frustración (13)

En salud pública, en el último tercio del siglo XIX, hay un debilitamiento de la salud ambiental progresivo que culmina con la desaparición del componente social de la salud y la consolidación de la versión tecnocrática y tecnológica. Con la introducción de la 
microbiología como dogma: las intervenciones públicas globales se centran en el control y tratamiento de los focos de riesgo para toda la población. Las crecientes desigualdades en salud se explican por la naturaleza de las enfermedades infecciosas y no infecciosas: para protegerse de las primeras la clase media necesita asegurarse de que toda la población está protegida, mientras que esto no parece ocurrir con las enfermedades no infecciosas (Hoy está claro que los problemas de abusos de drogas y SIDA que no respetan las clases sociales han producido una respuesta rápida y cuantiosa al igual que lo hicieron en su día las epidemias de cólera). La salud pública, en cuanto a práctica del Estado, se escinde en un funcionariado destinado a la higiene y policía sanitaria y unos profesionales destinados a la asistencia clínica. La consolidación del Estado burgués, a finales del siglo XIX como referencia universal (la social-democracia, se aparta de la perspectiva revolucionaria aceptando la actuación dentro del marco institucional del Estado). Pero son las violentas luchas obreras surgidas con la industrialización, la toma de conciencia de clase de los trabajadores y la creación de poderosos partidos y sindicados, quienes fuerzan la creación del primer Ministerio de Salud en Alemania, en 1871, y la creación por Bismarck del Seguro Obligatorio de Enfermedad, que va a dar asistencia a los obreros en la vejez, la invalidez y los accidentes, medidas que el movimiento de reforma sanitaria venía propugnado desde mediados del siglo frente a la teoría microbiológica (Pasteur, Koch). Pioneros progresistas de la salud pública como Wirchow o Neumann señalan que las causas de las epidemias son tanto sociales como físicas, solicitando medidas sociales y la organización de una estructura sanitaria pública (14).

La idea de higiene mental, de salud mental, surge con el siglo. Recordemos la Liga de Higiene Mental y su multitudinario ler Congreso, celebrado en 1929 en Washington que reúne a cerca de 5000 personas de 53 países (15) (1). Tras la Primera Guerra Mundial la Sociedad de Naciones crea, en 1920, la Oficina Internacional de Higiene y la Oficina Panamericana de Salud. La revolución soviética establece el primer servicio nacional de salud. Pero será después de la II Guerra Mundial cuando se inicia la reforma psiquiátrica dentro de un amplio movimiento de reformas sociales y sanitarias que va a configurar el Estado del Bienestar.

Es un compromiso ético de las fuerzas políticas vencedoras: también un imperativo social. Tras el horror bélico se crea la esperanza en las poblaciones de un mañana mejor, de una sociedad más solidaria y más justa. En este sentido, en 1952 la recién creada Organización Mundial de la Salud (1946) proclama su definición de la salud, una declaración de intenciones progresista que vincula la salud al bienestar físico, psíquico y social, y no sólo a la ausencia de enfermedad. La protección de la salud va a formar parte de las mejoras de las condiciones de vida, del nuevo proyecto de sociedad que supone el Estado del Bienestar. Desde los documentos iniciales que dan lugar al Servicio Nacional de Salud inglés -el primero y más paradigmático durante mucho tiempo- el informe Beveridge, en plena guerra, en 1942, se pretende afrontar a lo que entonces se definen como los cinco gigantes que amenazaban a la humanidad: indi- 
gencia, enfermedad, ignorancia, miseria y desempleo, a través de un seguro global y de los servicios públicos.

Se organizan nuevos sistemas nacionales de salud en Europa y Canadá, más equitativos y universales, y se configura una nueva epidemiología aplicada a las enfermedades no infecciosas. Los sistemas nacionales de salud incorporan la actividades preventivas. La integración de la psiquiatría en la sanidad general, la desinstitucionalización y la salud mental comunitaria constituyen los elementos fundamentales del movimiento de reforma psiquiátrica. Hay un desplazamiento conceptual de la psiquiatría a la salud mental. Del servicio de psiquiatría se pasa a los servicios de salud mental. $O$ dicho de otra manera de la noción de enfermedad y su tratamiento pasamos a una noción más amplia que significa tanto la condición deseada para el bienestar de los individuos como a las acciones necesarias para conseguirla.

La fuerza renovadora de los movimientos sociales de los años sesenta van a influir en la psiquiatría (Acta Kennedy en EE.UU., reforma antiinstitucional Basagliana, antipsiquiatría inglesa) y en la potenciación de nuevas orientaciones para la sanidad pública. En 1974 el Informe Lalonde del gobierno de Canadá, con el se configura la Nueva Salud Pública, señala que en lugar de gastar tanto en los aspectos asistenciales (hay que tener en cuenta la crisis económica de 1973 que muestra los límites al desarrollo) debe dirigirse la atención hacía los factores que inciden en la aparición de las enfermedades crónicas. La conferencia de Alma Ata en 1978 constata que el aumento de los presupuestos sanitarios dirigidos a los capítulos asistenciales no se corresponden con una mejora de la salud, proponiendo trasladar el eje de la atención desde la asistencia hospitalaria a la atención primaria, preventiva y promotora de salud. La OMS propone como objetivo «Salud para todos en el año 2000», un conjunto de medidas y recomendaciones encaminadas a la promoción de estilos de vida dirigidos a la salud, a la prevención de enfermedades evitables y al establecimiento de servicios sanitarios. El suma: el sujeto de intervención del sistema de salud se traslada a toda la población y no sólo al sujeto enfermo. Se pretende ir más allá de la morbilidad conocida: ésa parte visible y pequeña de la morbilidad y la vulnerabilidad. La responsabilidad de la sanidad pública ya no es sólo la reparación del daño, la «curación», sino hacerse cargo del cuidado sanitario de la población. Hay un descentramiento de los sistemas de salud que tiene que salir fuera, salir de los hospitales a la comunidad, a la población. Supone el desarrollo de la Atención Primaria y de los programas preventivos. La salud pública amplía sus miras: el médico encuentra de nuevo lo social, los factores sociales que condicionan el enfermar. Se encuentra de nuevo con aquellas famosas palabras del fundador de la mima, Wirchow: la medicina y la salud pública son intervenciones sociales; y los cambios políticos, sociales y económicos son intervenciones de salud pública en su sentido más profundo . La medicina se piensa como rama de la salud pública. La psiquiatría como parte de la salud mental.

Hernán San Martín y Vicente Pastor, en un libro publicado en 1988, Salud comunitaria.Teoría y práctica, cuando aún estaba de actualidad la atención comunitaria en España (la Ley General de Sanidad se aprueba en 1986), escriben: «Se puede hablar de 
INFORMES

salud comunitaria cuando los miembros de una comunidad, conscientes de constituir una agrupación de intereses comunes, reflexionan y se preocupan por los problemas de salud de la comunidad, expresan sus aspiraciones y necesidades, y participan activamente, junto a los servicios de salud, en la solución de sus problemas, a través de los programas locales de salud. En realidad, lo que llamamos salud comunitaria es el programa de salud pública local, planificado en base a los problemas y necesidades de cada comunidad, ejecutado con la participación de la comunidad. Se trata de una estrategia para aplicar localmente los programas de salud pública, y no de una especialidad nueva de la salud pública, y menos de la medicina»(16).

La Salud Mental Comunitaria va a designar un modelo de atención caracterizado por varios desplazamientos: a) del sujeto enfermo a la colectividad; b) del espacio hospitalario (sobre todo el manicomial) a la comunidad; del psiquiatra al equipo. La Salud Mental Comunitaria incorpora nociones de salud pública y además del trabajo clínico tradicional establece acciones para la población general y grupos de riesgo: la territorialización, la universalidad y la integración de los recursos de cada Area de Salud son requisitos indispensables, así como el trabajo con otras instancias comunitarias.

La salud mental comunitaria significa un modelo de organización de servicios y un modelo de atención clínico asistencial. Un modelo que la reforma sanitaria española ensaya con el área de salud y que se concreta en la reforma de la atención primaria de salud (17) (2)

\section{La salud mental en el mundo y el despiece del estado del bienestar}

En los años ochenta se evidencia la inflexión de modelo que nos conducirá en la década siguiente a la globalización. Informes del Banco Mundial responsabilizan al Estado del Bienestar de la crisis económica iniciada una década atrás. Los gobiernos europeos se plantean recortes a las prestaciones sanitarias y sociales: pensiones, atención sanitaria, servicios sociales, educación, seguro de desempleo, para conseguir una supuesta mejora de la inversión y el empleo. En 1987 el Banco Mundial hace público un informe sobre «financiación de los servicios sanitarios en los países en desarrollo: un programa de reformas», recomendando una serie de medidas, aplicables a prácticamente todos los países, que pueden resumirse en:

1) trasladar a los usuarios los gastos en el uso de las prestaciones; 2) ofrecer esquemas de aseguramiento para los principales casós de riesgo; 3) utilizar de forma eficaz los recursos privados; 4) descentralizar los servicios sanitarios públicos».

Seis años después, en el «informe sobre desarrollo mundial de 1993», dedicado a «invertir en salud», los expertos del Banco Mundial insisten en medidas sanitarias que tiendan a disminuir la carga global de morbilidad al menor coste posible, proponiendo dos estrategias: 1) la introducción de las fuerzas del mercado en el ámbito sanitario; y 2) la 5:56-64), «algo más que un cambio de técnicas; implica nuevas actitudes en el quehacer cotidiano de las profesiones sanitarias y, por supuesto, una planificación y ordenación de los sistemas públicos que la posibiliten*. No es posible una psiquiatrfa comunitaria en sistemas sanitarios liberales como el de EEUU, más allá de centros pilotos, como se demostro con el fracaso de los Centros comunitarios surgidos del Acta Kennedy de 1963 . $\star$ La 
«correcta» asignación de recursos públicos con criterios de eficiencia técnica e instrumental, por medio de intervenciones de alta efectividad y bajo coste.» el Banco Mundial apela al «homo oeconomicus» frente a factores de legitimación social.

Estos informes del Banco Mundial nos sitúan en el escenario sanitario de fin de milenio, lejos de la salud para todos y la salud sostenible de la OMS, y poco proclive para la Nueva Salud Pública o la Psiquiatría Comunitaria. Son el terreno abonado para el regreso de la neuropsiquiatría, del pensamiento biomédico, está vez disfrazado de eficiencia a través de la medicina basada en la evidencia, último invento del pensamiento único en pro de un vademécum universal.

Y sin embargo, la epidemiología constata otras urgencias y necesidades, pues mientras la morbilidad somática está en descenso en todo el mundo, hay un aumento de las enfermedades mentales que se consideran una de la epidemias del próximo milenio por el incremento de los factores adversos tanto en los países pobres como en el primer mundo. El informe salud mental en el mundo, publicado en 1997 por la ONU aboga, ante este previsible aumento de la morbilidad psiquiátrica en los próximos años, intervenciones sobre la calidad del medio social, la violencia, la desigualdad, estilos de vida no saludables : factores que influyen en la vulnerabilidad de las personas y en el curso que van a seguir las enfermedades (18).

Como señalaba en otro lugar, un articulo publicado en Siso Saude (19), ni la psiquiatría biológica ni el mercado como política de gobierno son una respuesta para el desarrollo de la salud mental. Hoy, cuando acabamos de celebrar el 50 aniversario de la Declaración Universal de los Derechos Humanos, la salud se impone, como un derecho inexcusable para los gobiernos. Y la sociedad de mercado funciona sin referencias éticas: no le cabe el individuo en tanto sujeto moral. En un editorial de la Revista Española de Salud Pública, editada por el Ministerio de Sanidad y Consumo, titulado «El cumplimiento de los derechos humanos: primera medida de salud pública», se recuerda que los modelos de mercado están fracturando los sistemas nacionales de salud y que la solución se encontraría en ligar el crecimiento económico al cumplimiento de los derechos humanos (20). 
INFORMES

\section{BIBLIOGRAFÍA}

(1) Castilla del Pino, C., Vieja y nueva psiquiatría, Madrid, Seminarios y ediciones, 1971

(2) Oñorbe, M., "Salud pública hoy y mañana", Revista de Administración Sanitaria 1997, 1 (2): 13-17

(3) Zambrano, M., Persona y democracia, Madrid, Siruela, 1996 p.135.

(4) Schreber, DP., Memorias de un neurópata (legado de un enfermo de los nervios), Barcelona, Argot, D.L. (2ªedición) 1986

(5) Eisenberg, L., "Naturaleza, entorno y crianza. El papel de la experiencia social en la transformación del genotipo en fenotipo". Psiquiatría Pública 1999, 5-6 (11): 139146.

(6) Marset Campos, P; Sáez Gómez, J., "La evolución histórica de la salud pública”. En: Martínez Navarro, F; Antó. JM; Castellanos, PL; Gili, M; Marset; P; Navarro, V; Salud Pública, Madrid, MacGraw-Hill. Interamericana, 1997.

(7) Pinel, PH., Tratado médico-filosófico de la enagenación mental o manía, Madrid, Nieva, 1988.

(8) Huertas, R., Del manicomio a la salud mental, Madrid, FISS 1992, p.37.

(9) Hegel ,G.W.F., Enciclopedia filosófica de las ciencias, Madrid, Alianza, 199711)

(10) Hegel. GWF., Obra citada

(11) Marx, C.; Engels, F., Obras escogidas, , Moscú, Editorial Progreso 1966, t.2,

(12) Desviat, M (Coord.). Epistemología y práctica psiquiátrica, Madrid, AEN 1990

(13) Albarracín Teulón, A., Las ciencias médicas en España. En: Huertas, R.;Romero, AI.; Álvarez, R. (Coord.), Perspectivas psiquiátricas, Madrid, CSIC, 1987

(14) Marset, P; Sáez, JM., Obra citada

(15) Beers, C., A Mind that Found Itself, New York, Doubleday, 1908

(16) San Martín, H.; Pastor, V., Salud comunitaria. Teoría y práctica, Madrid, Díaz de Santos, 1988

(17) Desviat, M., “Acción de Salud mental en la comunidad", Revista de la Asociación española de Neuropsiquiatría, 1982 (2) 5:56-64

(18) Desjarlais, R.; Eisenberg, L.; Good. B.; Kleiman, A, Salud mental en el mundo, Washington: OMS/OPS 1997

(19) Desviat, M. "La psiquiatría comunitaria y la salud mental en el fin del milenio", Siso-Saude, 200, 33: 46-57.

(20) Jiménez García-Pascual,R., "El cumplimiento de los derechos humanos: primera medida de Salud Pública", Rev Esp Salud Pública 1998; 72; 477-480

*Psiquiatra, director gerente del Instituto Psiquiátrico Servicios de Salud Mental José Germain, C/ Luna, 1, 28911 Leganés, Madrid. mdesviat@ipsqgermain.es 